\title{
O OLHAR DOS PROFESSORES DO ENSINO FUNDAMENTAL SOBRE A VIOLÊNCIA NAS ESCOLAS PÚBLICAS DA CIDADE DE JOÃO PINHEIRO
}

\section{THE VIEW OF FUNDAMENTAL TEACHERS ON VIOLENCE IN PUBLIC SCHOOLS IN THE CITY OF JOÃO PINHEIRO}

\author{
Aline Lopes de Oliveira ${ }^{1}$ \\ Pâmela Cristina Carneiro Lopes ${ }^{2}$ \\ Ailton de Souza Gonçalves ${ }^{3}$ \\ https://doi.org/10.29327/216986.1.1-6
}

RESUMO: O presente estudo aborda a visão dos professores do Ensino Fundamental das escolas de João Pinheiro, sobre a violência no ambiente escolar no ano de 2019. O principal objetivo que levou a essa pesquisa foi investigar a que se deve esse aumento dos conflitos e das manifestações de violência no espaço escolar e como os professores das instituições trata esse assunto com os alunos. Assim foi necessária uma pesquisa para identificar a visão dos professores em relação à violência no ambiente escolar; investigar quais são as estratégias que vem sendo utilizadas na prevenção e mediação desses conflitos; averiguar quais são os fatores que levam o aluno a ser violento e verificar os impactos que a violência pode trazer no processo ensino aprendizagem no ambiente escolar. A metodologia utilizada foi uma pesquisa de abordagem qualitativa, a modalidade de pesquisa deu-se através da pesquisa bibliográfica e da pesquisa de campo que teve como instrumento um questionário. Foi compreendido que a violência é um problema social e está ligada a estrutura familiar, no entanto, a melhor forma para prevenir e mediar

\footnotetext{
${ }^{1}$ Licenciada do curso de Pedagogia EAD da Faculdade do Noroeste de Minas - FINOM. E-mail: alinelopesoliveira2015@gmail.com

${ }^{2}$ Licenciada do curso de Pedagogia EAD da Faculdade do Noroeste de Minas - FINOM. E-mail: pamelacristunacarneito@gmail.com

${ }^{3}$ Doutor em Ciências da Religião pela PUC-Goiás. Licenciado em Filosofia, coordenador do Núcleo de Apoio Psicopedagógico (NOP) e do Núcleo de Iniciação Científica (NIP) e atua ainda como docente das faculdades FINOM e Tecsoma Membro do Grupo de pesquisa Avaliação e Ética (GPAE). http://lattes.cnpq.br/5451317417757393. E-mail: ailtongoncalves@finom.edu.br
}

Educação In Loco, v.01, n. 01, jan.-jun. 2020 - ISSN 2675-4304 
é através do diálogo, da conscientização e do trabalho em equipe/ educação, família e sociedade.

Palavras-chave: violência, conflito, agressividade, educação.

ABSTRACT: This study addresses the view of elementary school teachers from João Pinheiro schools about violence in the school environment in 2019. The main objective that led to this research was to investigate why this increase in conflicts and manifestations of violence in the school space and how the teachers of the institutions treat this subject with the students. Thus, research was needed to identify teachers' view of violence in the school environment; investigate which strategies have been used to prevent and mediate these conflicts; to investigate what are the factors that lead the student to be violent and to verify the impacts that the violence can bring in the teaching-learning process in the school environment. The methodology used was a qualitative approach research, the research modality was through bibliographic research and field research that had a questionnaire as instrument. It has been understood that violence is a social problem and is linked to family structure, however, the best way to prevent and mediate is through dialogue, awareness and teamwork / education, family and society.

Keywords: violence, conflict, aggressiveness, education.

\section{Introdução}

Sabe-se que a violência escolar não é recente, desde os primórdios, esse problema afeta o âmbito escolar, mas é notório que a cada dia se agrava cada vez mais, com isso não basta repreender a ação, é necessário que a escola desenvolva projetos político pedagógico de prevenção à violência e que vá além do ensinoaprendizagem. Nesse projeto deve haver a participação de todos, como a comunidade, os pais, os alunos e todos envolvidos no processo educacional. 
A violência pode ser caracterizada por física e moral, um exemplo mais comum de violência moral no ambiente escolar é o bullying. Para ELIAS (2011, p. 17) "o bullying é caracterizado por exclusão social, agressões verbais ou físicas, ameaças, exposição indevida nas redes sociais e o assédio sexual".

As escolas de todo país convivem com esse problema, e o professor precisa abordar de forma mais ampla e administrar aulas que integrem e promovam uma socialização entre os alunos, para que sejam respeitadas as diferenças seja ela qual for, e essa integração cria um rico espaço de aprendizagens e desenvolve habilidades como flexibilidade e a aceitação do outro.

O motivo que nos levou a esse tema, primeiramente por ser um assunto que está em evidência seria mais fácil discorrer sobre o tema, outro motivo é que estamos inseridas no âmbito escolar durante 3 anos na função de monitoras de uma determinada escola de Educação Infantil, onde presenciamos várias atitudes agressivas por parte dos alunos, o que nos gerou uma grande preocupação, pois são crianças que acabaram de ingressar na vida escolar e já demonstram resistência em aceitar as diferenças existentes em um ambiente escolar.

Por isso, acreditamos que essa pesquisa poderá contribuir e impulsionará professores a rever seus projetos e desenvolver ações imediatas que possa amenizar a violência e resolver conflitos gerados entre os alunos.

A relevância social do presente trabalho será entender e auxiliar com a nossa pesquisa, caminhos que norteiam e amenizam o problema da violência dentro das escolas. Promover discursões e buscar alternativas para que a partir desta pesquisa, possa também, trazer resultados positivos para prevenção e mediação da violência dentro do ambiente escolar.

Início nossa justificativa científica com as palavras de Demo (2005, p.14), "quem ensina carece pesquisar, quem pesquisa carece ensinar". A atividade docente e a pesquisa são elementos inseparáveis, pois para ser professor é preciso criar caminhos através da pesquisa e proporcionar condições e possibilidades para aprimoramento intelectual e acadêmico, para se tornar um professor 
crítico e reflexivo. E a importância da pesquisa dentro do nosso projeto será conhecer e aprofundar nas problemáticas relacionadas à violência, que estão inseridas cada vez mais nas instituições de ensino.

O desenvolvimento desse projeto terá como principal objetivo investigar a que se deve esse aumento dos conflitos e das manifestações de violência no espaço escolar e como os professores das instituições trata esse assunto com os alunos. E para aprofundar no assunto será necessária uma pesquisa de campo para identificar a visão dos professores em relação à violência no ambiente escolar; investigar quais são as estratégias que vem sendo utilizadas na prevenção e mediação desses conflitos; averiguar quais são os fatores que levam o aluno a ser violento e verificar os impactos que a violência pode trazer no processo ensino aprendizagem no ambiente escolar.

A princípio as hipóteses dessa pesquisa partiram do pressuposto que a violência é um fenômeno que preocupa e que deve ser combatida com a participação de todos e com ações específicas. Por isso é necessário que ao detectar um aluno que demostra agressividade dentro da sala de aula com dificuldades de socialização e aprendizagem, o professor passe a observá-lo mais atentamente e faça um acompanhamento individual, e se for o caso que peça ajuda há profissionais especializados para que juntos possam identificar o motivo que justifique as atitudes violentas.

Segundo Abramovay (2004, p.93) "a construção do bom clima na escola passa, necessariamente, por um trabalho pautado no combate às mais variadas formas de exclusão, tão presentes na sociedade". O fator principal para a geração de um jovem agressivo pode-se associar ao fato da realidade social e a exclusão do agressor, sendo que, a maior parte dos conflitos é gerada devido a manifestações de intolerância e de preconceito. Mas também pode ser um indicativo que o jovem talvez esteja sofrendo agressões por parte dos familiares e isso afeta no convívio escolar que pode levar até mesmo a evasão. Por isso é de suma importância que o professor adote a estratégia da conquista, pois é uma poderosa arma para se aproximar dos alunos agressivos. É conhecendo a realidade de cada 
um que se pode entender os motivos que o levam a agressividade e assim, procurar meios para minimizar esse desequilíbrio emocional.

\section{Objetivos}

O presente trabalho tem como objetivo averiguar a "Violência Escolar" na visão de professores do Ensino fundamental das escolas da Rede Pública de João Pinheiro-MG, que está localizada no Noroeste de Minas, com uma população de 45.260 habitantes, sendo que $18,8 \%$ vivem na área rural e $81.2 \%$ na área urbana, segundo o Censo Demográfico 2010 do IBGE. No município segundo dados do IBGE de 2017, há 28 escolas com Ensino Fundamental, 372 docentes atuando no Ensino Fundamental e 6.272 matriculados no Ensino Fundamental.

Assim o trabalho, vai buscar compreender como os professores do Ensino Fundamental da rede pública vê o problema da violência escolar; Conhecer as estratégias usadas pelos professores para diminuir as ocorrências de violência no ambiente escolar; Analisar os fatores que geram comportamentos de violência nos alunos; Saber quais os fatores que geram comportamentos de violência nos alunos.

\section{Metodologia}

Embasados bibliograficamente e em pesquisa qualitativa, a pesquisa foi realizada nas Escolas Estaduais do município de João Pinheiro - MG, nesse sentido, desenvolveu-se uma pesquisa de abordagem qualitativa, que de acordo com Tozoni-Reis (2009) pesquisa em educação é essencialmente qualitativa, porque busca entender e interpretar o fenômeno pesquisado e não quantificá-lo. Segundo Fazenda (2002) a pesquisa contribui na aquisição de conhecimento científico, por meio do aprofundamento na historiografia da área pesquisada, para organizar com o conhecimento empírico e através da pesquisa de campo e de dados coletados, produzir um conhecimento novo e sistematizado. 
A exploração de dados possibilitou para que percebêssemos a teoria e vivenciar a prática nos eventos norteadores desse artigo. Levaram-se em consideração as indagações sobre a aceitação e a realização do projeto pesquisado, o acompanhamento pedagógico dos profissionais educadores diante dos alunos.

Usamos como instrumento um questionário, aplicado a oito professores atuantes no Ensino Fundamental das escolas públicas de João Pinheiro. O objetivo foi extrair informações as quais estão presentes em artigos e materiais relacionados ao tema escolhido, os quais disponibilizados na internet e em literaturas físicas nas quais executamos o apanhado de tudo que usamos.

De acordo com Tozoni-Reis (2009) a entrevista é uma técnica muito utilizada nas pesquisas qualitativas, e tem como objetivo buscar informações através da fala de narradores para serem investigadas, e esse instrumento é fundamentado em questões predefinidas que devem ser claras, precisas e coerentes que levem a respostas objetivas.

Portanto, as metodologias adotadas, objetivaram obter mais elementos que nortearam a investigação, e também conhecer a visão de professores atuantes a respeito da violência no espaço escolar, e quais são as estratégias de intervenção que eles sugerem que podem ser utilizadas para a mediação e o combate da violência que cada vez mais está inserida no âmbito escolar.

A busca realizada nos permitiu uma bela reflexão sobre o nosso papel enquanto pesquisadoras, a oportunidade é sem igual.

\section{Resultados e Reflexões}

A violência apesar de se manifestar em todas as classes sociais ela parece estar mais presente e em maior número de incidências em escolas de bairros pobres e entre alunos que demonstram não ter uma estrutura familiar.

Segundo os dados coletados do IBGE através da Pesquisa Nacional de Saúde do Escolar de 2012, foi realizado um estudo na Europa e na América do Norte, Global Schod-Based Student Health Survey- GSHS, pela OMS, onde apontou que $14 \%$ dos alunos com 
11 anos de idade estiveram envolvidos em uma briga com luta física, por pelo menos três vezes nos 12 meses anteriores à pesquisa, 13,0\% aos 13 anos de idade e 10,0\% aos 15 anos de idade. (CURRIE et al., 2012).

E ainda sobre o IBGE agora sobre o bullying, Dados e Pesquisa de Comportamento de Saúde em crianças em idade escolar (Health Behaviour in School-Aged Children-HBSC), da OMS, para países da Europa e América do Norte, mostraram que 13,0\% dos alunos com 11 anos de idade sofreram bullying na escola por no mínimo duas vezes nos 2 meses anteriores à pesquisa $12,0 \%$ aos 13 anos de idade e 9,0\% aos 15 anos de idade. (CURRIE et al., 2012).

Através das pesquisas realizadas pôde-se constatar-se que, de acordo com o avanço da idade diminuíram-se as incidências de violência através de agressão física e bullying.

\section{Uma breve análise da violência escolar no Brasil}

Conforme as palavras da autora Abramovay e Rua (2003, p.26) os primeiros estudos no Brasil voltado ao tema violência escolar iniciaram na década de 1970, onde pesquisadores e pedagogos demostraram grande preocupação com o aumento do índice de violência e crimes. Em 1980 foram destacadas várias pesquisas feitas por instituições públicas e privadas realizadas em maior parte por profissionais da área das Ciências Sociais do que da área da Educação. Nessa década começam a dar ênfase no chamado violência à escola, que são atos praticados por alunos, como pichações e depredações. Já na década de 1990 a violência à escola continuou, mas foi aliada a outra violência como a interpessoal, referida as agressões físicas e verbais.

Segundo o pesquisador Edilberto Sastre (2009, p.06), de 1980 a 2009 a maior parte dos trabalhos acadêmicos que discorre sobre o tema violência escolar, cerca de $95 \%$ não foram publicados, ou seja, falta dar mais visibilidade aos trabalhos já feitos. Portanto, o que a sociedade conhece sobre violência escolar deve-se muitas vezes a fatos que foram notícias na mídia. Mas segundo Sastre, a partir de 2009 houve um grande avanço a respeito da visibilidade de trabalhos 
acadêmicos realizados sobre o tema, isso indica que o tema violência cada vez mais desperta a atenção de toda a sociedade e não apenas na área da Educação e Psicologia.

De acordo com Sastre (2009, p.20) no Brasil existem várias instituições que trata do tema violência escolar, entre elas a UNESCO, ONG's, o Ministério de Educação e Secretarias Estaduais de Educação. Em 2001, o Ministério da Educação através da Secretaria de Educação distribuiu kits chamados "Parâmetros em ação" com o intuito de ajudar os professores em seu trabalho de formação de cidadãos críticos, reflexivos e preparados para a convivência com o diferente. Outros programas foram lançados como "Programa Brasil sem homofobia", "Programa Nacional Paz nas Escolas" e também livros como "Educação anti-racista, caminhos abertos". De acordo com o autor, o Brasil realiza pesquisas, programas e financiam estudos sobre a violência e segundo essas pesquisas os jovens entre 15 e 24 anos são classe mais sujeita à violência. Em 2011 a UNESCO lançou o "Programa Abrindo Espaços" e em 2004 se transformou em política pública nacional com objetivo de oferecer atividades esportivas, artísticas, culturais e formação inicial durante os fins de semana nos espaços da escola.

No contexto geral, é difícil atribuir a culpa a alguém pelo o auto índice de violência no ambiente escolar, mas requer iniciativas imediatas para a mediação dessas ações e que devem partir dos pais, professores, gestores escolares e da sociedade em si. A escola precisa ser vista como um lugar de transformação e não apenas de transmissão de conhecimentos, é necessário investir na inclusão de valores no currículo, na melhoria da relação professor-aluno e estimular o desenvolvimento de qualidades individuais como a autoestima e a tolerância.

\section{Histórico de violência escolar a nível local}

Para se falar da violência a nível local, ainda faltam dados e pesquisas de campo mais abrangentes para que se possa apropriar-se do assunto mais detalhadamente. Todas as ocorrências registradas na região de João Pinheiro e entorno, vieram a público através das redes 
sociais e da mídia, e as práticas registradas que chegaram a público são de agressões verbais e físicas de aluno-aluno e de alunoprofessor, de abuso sexual de colegas da mesma turma e o bullying que se acredita ser o maior número de incidências ocorridas dentro das escolas. Mas sempre quando acontecem esses episódios, as instituições procuram ocultar os fatos para não prejudicar a imagem dos envolvidos e da instituição.

A pesquisa segundo Tozoni (2009, p.08) é uma forma de construir conhecimentos para compreender e interpretar a realidade de cada ser, pois a nossa sociedade é diversificada e cada indivíduo tem sua maneira de pensar e agir, por isso as ações projetadas acerca das problemáticas deve estar coerente com a realidade de cada comunidade.

Portanto, a violência é um desafio a ser vencido, e isso requer ações conjuntas com a sociedade, com os gestores públicos, com os pais, com os gestores escolares e professores, em prol da construção da construção de uma sociedade pacífica e tolerante com as diversidades. 


\section{Referências bibliográficas}

ABRAMOVAY, Miriam. Escolas Inovadoras: experiências bemsucedidas em escolas públicas. Brasília: Editora UNESCO, 2004. ABRAMOVAY, Miriam; Rua, Maria das Graças. Violência nas escolas. Brasília: Editora UNESCO Brasil, 2003.

ELIAS, Maria Auxiliadora. Violência Escolar: Caminhos para compreender e enfrentar o problema. São Paulo: Editora Ática, 2011. FAZENDA, Ivani. Metodologia da Pesquisa Educacional. $8^{\circ}$ edição. São Paulo: Editora Cortez, 2002.

IBGE, 2009. Análise dos Resultados. Disponível em: http://www.ibge.gov.br/home/estatística/população/pense/comentário s.pdf Acessado em 10/Setembro/2019.

SASTRE, 2010. Panorama dos Estudos sobre Violência nas escolas no Brasil: 1980-2009. Disponível em: http://portal.mec.gov.br/index. php?option=comdocman\&view=download\&alias=3900-panorama-estudo-violênciaescolas\&Itemid $=30192$ Acessado em 12/ Setembro/2019. TOZONI-REIS, Marília Freitas de Campos. Metodologia da Pesquisa. $2^{\text {a }}$ edição. Curitiba: IESDE Brasil S.A, 2009. 